\title{
Genetic and antigenic characterization of avian influenza H9N2 viruses during 2016 in Iraq
}

\author{
Nadira S. Mohamed ${ }^{1 \dagger}$, Ahmed Kandeil ${ }^{2 \dagger}$, Ibrahim A.H. AL-Zubaidy ${ }^{3}$, Ghazi Kayali ${ }^{4,5}$ and Mohamed A. Ali ${ }^{*}$ \\ ${ }^{1}$ Department of Genebank and Genetic Sequence, Forensic DNA Research and Training Center, \\ Al-Nahrain University, Baghdad, Iraq \\ ${ }^{2}$ Center of Scientific Excellence for Influenza Viruses, Water Pollution Research Department, \\ Environmental Research Division, National Research Centre, Giza, Egypt \\ ${ }^{3}$ Unit of zoonotic diseases researches, College of Veterinary Medicine, University of Baghdad, Baghdad, Iraq \\ ${ }^{4}$ Department of Epidemiology, Human Genetics, and Environmental Sciences, \\ University of Texas Health Sciences Center, Houston, TX, USA \\ ${ }^{5}$ Human Link, Hazmieh, Lebanon \\ ${ }^{\dagger}$ These authors contributed equally to this work
}

\begin{abstract}
Background: Little is known about the antigenic and genetic characteristics of influenza A viruses circulating in poultry in Iraq.

Objective: This study describes the genetic and antigenic characteristics of the detected avian influenza H9N2 viruses in Iraq during 2016.

Methods: Full genome sequences of two H9N2 viruses isolated from chickens in Iraq during 2016 were assembled. Antigenic analyses of Iraqi H9N2 viruses and contemporary H9N2 isolates from Lebanon and Egypt were performed by hemagglutination inhibition assay.

Results: Phylogenetic analysis of surface glycoproteins and internal segments (PB2, PA, NP, M, and NS) indicated that the Iraqi H9N2 viruses were closely related to G1-like lineage of H9N2 viruses isolated from Pakistan and Iran indicating possible epidemiological links. The PB1 segments of the current characterized H9N2 viruses were not related to any of the previously characterized H9N2 viruses and closely similar to H7N7 virus detected in chickens in Germany in 2015. Multiple genetic determinants for virulence and mammalian transmission were characterized in the characterized H9N2 viruses in Iraq. The antigenic analysis showed a close relationship between H9N2 viruses in Iraq and contemporary H9N2 viruses in Egypt and Lebanon. Like H9N2 viruses, Iraqis H9N2 virus bound to human-like receptor rather than avian-like receptor thus represent a public health risk.

Conclusion: Active surveillance of avian influenza virus in poultry and migratory birds should be adopted to monitor the genesis and emergence of new viruses in Iraq.
\end{abstract}

Keywords: Avian influenza virus, H9N2, Iraq.

\section{Introduction}

Influenza A virus (IAV) H9N2 subtype was first characterized in 1966 after isolation from turkeys in the United States (Homme and Easterday, 1970). Since the 1990s, H9N2 viruses have spread in several regions of the world, including East and Central Asia, Africa, Europe, and the Middle East and were characterized in different types of avian (Naeem et al., 1999; Wu et al., 2015) and mammalian hosts (Peiris et al., 1999; Saito et al., 2001; Guo et al., 2005; Gomaa et al., 2018). G1like H9N2 viruses are the most prevalent genotypes that have further diversified into four distinct groups A, B, C, and D (Fusaro et al., 2011).

During 2004-2007, several outbreaks associated with H9N2 virus infection were recorded in Iraq causing remarkable economic losses in the poultry industry with mortality rates up to $70 \%$ in broiler chickens and $5 \%-10 \%$ in layer chickens and breeder chickens (Khamas, 2008). Avian influenza virus (AIV) H9N2 infection was mostly accompanied by Newcastle Disease Virus (NDV) infections. Vaccination using bivalent inactivated oil emulsion vaccine of NDV and H9N2 viruses was used intensively in broiler flocks to control the disease (Kraidi et al., 2017). Nonetheless, several studies recorded $\mathrm{H} 9 \mathrm{~N} 2$ infection in broiler chickens suffering from respiratory signs from several provinces in the Middle and Southern of Iraq during 2011-2015 (Al-Dabhawe et al., 2013; Al-Mohana et al., 2013; Kraidi et al., 2017). Furthermore, H9N2 was detected as a predominant subtype in wild birds at many geographical regions of Iraq (Abdul-Sada, 2015). Little is known about the genetic and antigenic characteristics of H9N2 IAVs in Iraq. Here, we describe the full genome sequence of H9N2 isolates 
from chickens in Iraq and compare the antigenic characteristics of these viruses to those currently circulating in Egypt and Lebanon.

\section{Materials and Methods \\ Sample collection and virus isolation}

A team of veterinarians collected 230 tracheal and cloacal swabs from broiler chicken farms from three provinces located in the center and east of Iraq (Baghdad, Babel, and Wasit) in the period of October 2016 to January 2017. The tips of the collected swabs were immersed in cooled viral glycerol-PBS transport medium [ $50 \%$ glycerol, $50 \%$ phosphate-buffered saline, penicillin $(2 \times 106 \mathrm{U} / \mathrm{l})$, streptomycin $(200 \mathrm{mg} / \mathrm{l})$, and amphotericin B $(250 \mathrm{mg} / \mathrm{l})]$. All the collected samples were inoculated in the allantoic cavities of 11-dayold specific pathogen-free embryonated chicken eggs and incubated for two days at $37^{\circ} \mathrm{C}$. At the end of incubation, $100 \mu \mathrm{l}$ allantoic fluid were tested by the hemagglutination test using $0.5 \%$ chicken red blood cells. The positive HA samples were subjected to viral RNA extraction, followed by the detection of IAV infection using real time PCR (rRT-PCR) that based on M gene (CDC, 2007). The IAV positive samples were further subtyped as previously described using rRTPCR (Kayali et al., 2014).

\section{Genetic characterization and phylogenetic tree} construction

Briefly, the first-strand cDNA from each isolate was synthesized using Superscript III Reverse transcriptase (Invitrogen, Carlsbad, CA) and Uni-12 primer (5'AGCRAAAGCAGG3') as per manufacturer's protocol. Using Phusion Master Mix kit (Thermo, Wilmington, Delaware), the desired genes of the H9N2 isolates were amplified using universal primers (Hoffmann et al., 2001). The purified PCR products were directly used for sequencing reactions at Macrogen sequencing facility (Macrogen, South Korea). Sequences were assembled using SeqManDNA Lasergene 7 software (DNASTAR, Madison, WI). The assembled sequences were submitted to GenBank (GenBank accession numbers: MH879789MH879803). MEGA 6.0 was used for phylogenetic tree construction by applying the neighbor-joining method with Kimura's two-parameter distance model and 1000 bootstrap replicates (Tamura et al., 2011). The trees included closely related H9N2 viruses from Middle Eastern countries, representative viruses from the groups A-D (Fusaro et al., 2011), major ancestral H9N2 strains, and other influenza virus subtypes with closely related of PB1 of Iraqis H9N2, as shown by a BLAST search.

\section{Antigenic characterization}

Antigenic analyses of Iraqi H9N2 viruses and contemporary H9N2 isolates from Lebanon and Egypt were performed by hemagglutination inhibition (HI) test using chicken antisera generated by vaccination of several chicken groups with different H9N2 antigens. Hyperimmune chicken sera of H9N2 inactivated vaccines were individually prepared using AI (A/chicken/Egypt/S4456B/2011, A/chicken/Egypt/ D9570B/2014, A/chicken/Egypt/D9817E/ 2014, A/pigeon/Egypt/S10408B/2014, A/pigeon/Egypt/ S10409A/2014, A/Bangladesh/10994/2011, A/quail/ Lebanon/272/2010, and A/Hong Kong/1073/1999) viruses as previously described (Kandeil et al., 2017). Polyclonal antibodies were used to construct antigenic cartography based on HI results and using the integrative matrix completion multi-dimensional scaling method (Cai et al., 2011).

Receptor binding assay (RBA)

RBA was determined for an AI A/chicken/ Iraq/4/2016(H9N2) virus as previously described (Matrosovich and Gambaryan, 2012). An avian A/ duck/Hong Kong/365/78 (H4N6) and a human A/ Hong Kong/1073/99 (H9N2) isolates, which had 3 '-sialyllactose $(\alpha 2,3-\mathrm{SL}$; avian like receptor) and 6 '-sialyllactose ( $\alpha 2,6-\mathrm{SL}$, human like receptor) binding preference, respectively, were used as a control for this assay. A coated 96-well plate with fetuin $(10 \mu \mathrm{g} / \mathrm{ml})$ was washed with washing buffer $(0.01 \%$ Tween 80 in $0.23 \mathrm{X}$ PBS) to remove excess of uncoated fetuin. The plate was blocked with PBS containing $1 \%$ bovine serum albumin (BSA) then incubated overnight with 64 hemagglutination units of $\mathrm{H} 9 \mathrm{~N} 2$ isolate from Iraq at $4^{\circ} \mathrm{C}$. The plate was washed with washing buffer 4 times. Biotinylated sialylglycopolymers, $\quad 3$ '-sialyllactose $\quad(\alpha 2,3-\mathrm{SL}$, Neu5Ac $\alpha 2-3 \mathrm{Gal} \beta 1-4 \mathrm{Glc}$ ), and 6 '-sialyllactose $(\alpha 2,6-\mathrm{SL}, \quad$ Neu5Ac $\alpha 2-6 \mathrm{Gal} \beta 1-4 \mathrm{Glc}) \quad$ (Glycotech, Gaithersburg, MD) were serially diluted in reaction buffer $[0.02 \%$ Tween $80,0.02 \%$ BSA, $1 \mu \mathrm{M}$ sialdase inhibitor (Zanamivir) and 1X PBS] at 96-well plate and were added to coated plate and incubated at $4{ }^{\circ} \mathrm{C}$ for 2 hours. The plate was washed $(4 \times)$ and incubated with $100 \mu \mathrm{L}$ of horse-radish peroxidase-conjugated streptavidin $(1: 1000)$ at $4^{\circ} \mathrm{C}$ for 1 hour. After a final wash, a volume of $50 \mu \mathrm{l}$ of the $o$-Phenylenediamine substrate was added to each well and incubated for $10 \mathrm{~min}$ at room temperature. The reaction was stopped using $1 \mathrm{~N}$ sulfuric acid, and absorbance was measured at $490 \mathrm{~nm}$.

\section{Results and Discussion}

Out of 230 collected samples from chickens, only two samples $(0.86 \%)$ from the same farm at Wasit province were positive for influenza $A$ and subtyped as H9N2 viruses and both were subjected to full genome sequencing. The HA and NA of the H9N2 isolates from Iraq showed high sequence homology $(97 \%-96 \%)$ with H9N2 strains previously isolated from commercial and backyard poultry flocks in Pakistan (Lee et al., 2016) belonging to group B of G1-like H9N2 viruses (Fig. 1). The HA of the detected H9N2 viruses in this study showed sequence identity $91 \%-88 \%$ with the previously characterized H9N2 strains from Iraq during 

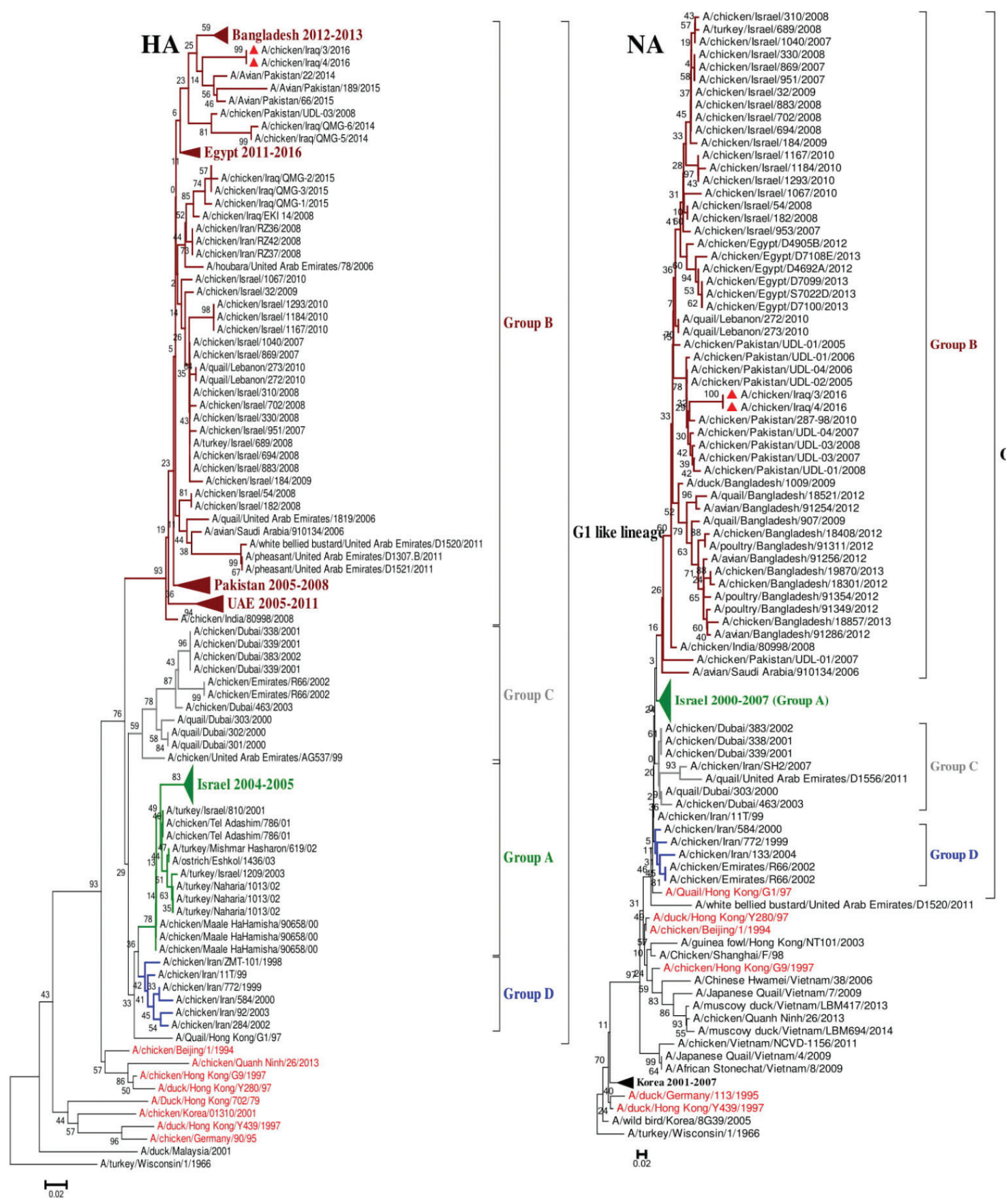

G1 Like lineage

Fig. 1. Phylogenetic trees of the nucleotide sequences of the HA and NA segments of H9N2 viruses isolated from Iraq comparing with representative H9N2 viruses isolated from different Asian and Middle Eastern countries. H9N2 isolates sequenced specifically for this study are labeled in red triangles. Reference H9N2 viruses were labeled with red color. The phylogenetic analysis was performed by using MEGA version 6. Four distinct groups A, B, C, and D of G1-like H9N2 viruses were distinguished by green, maroon, gray, and blue colors, respectively.

2014-2015. Similarly, analysis of the internal segments (PB2, PA, NP, M, and NS) indicated that these segments were closely related to group B H9N2 viruses (Fig. 2). The PB1 segments of Iraqi H9N2 viruses were not related to any of the previously characterized H9N2 viruses and showed 98\% nucleotide sequence similarity with the PB1 of AI H7N7 virus previously detected in chickens in Germany in 2015 (OIE, 2015).

To identify amino acids that may be involved in virus virulence, pathogenicity, mammalian transmission, receptor-binding specificity, and antiviral drugs resistance, we analyzed the deduced amino acid 


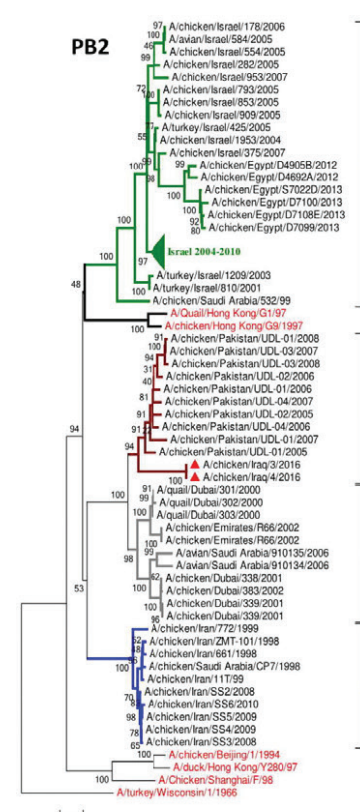

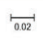

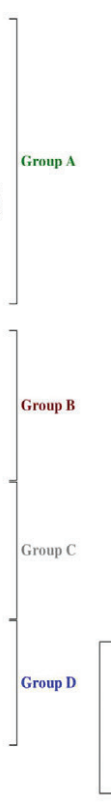

D D

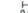
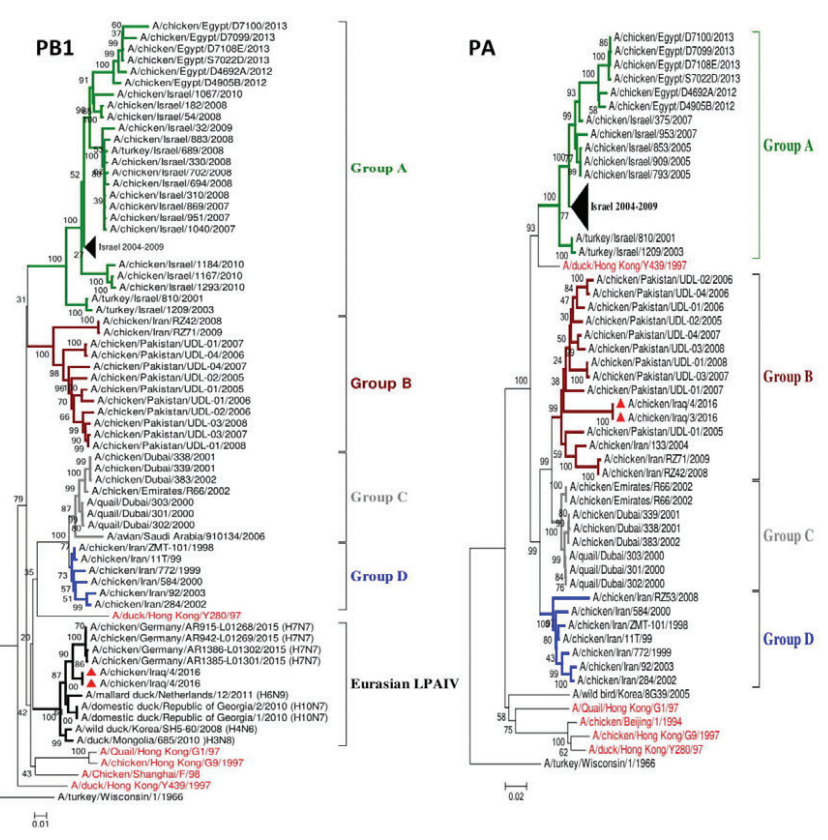

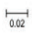
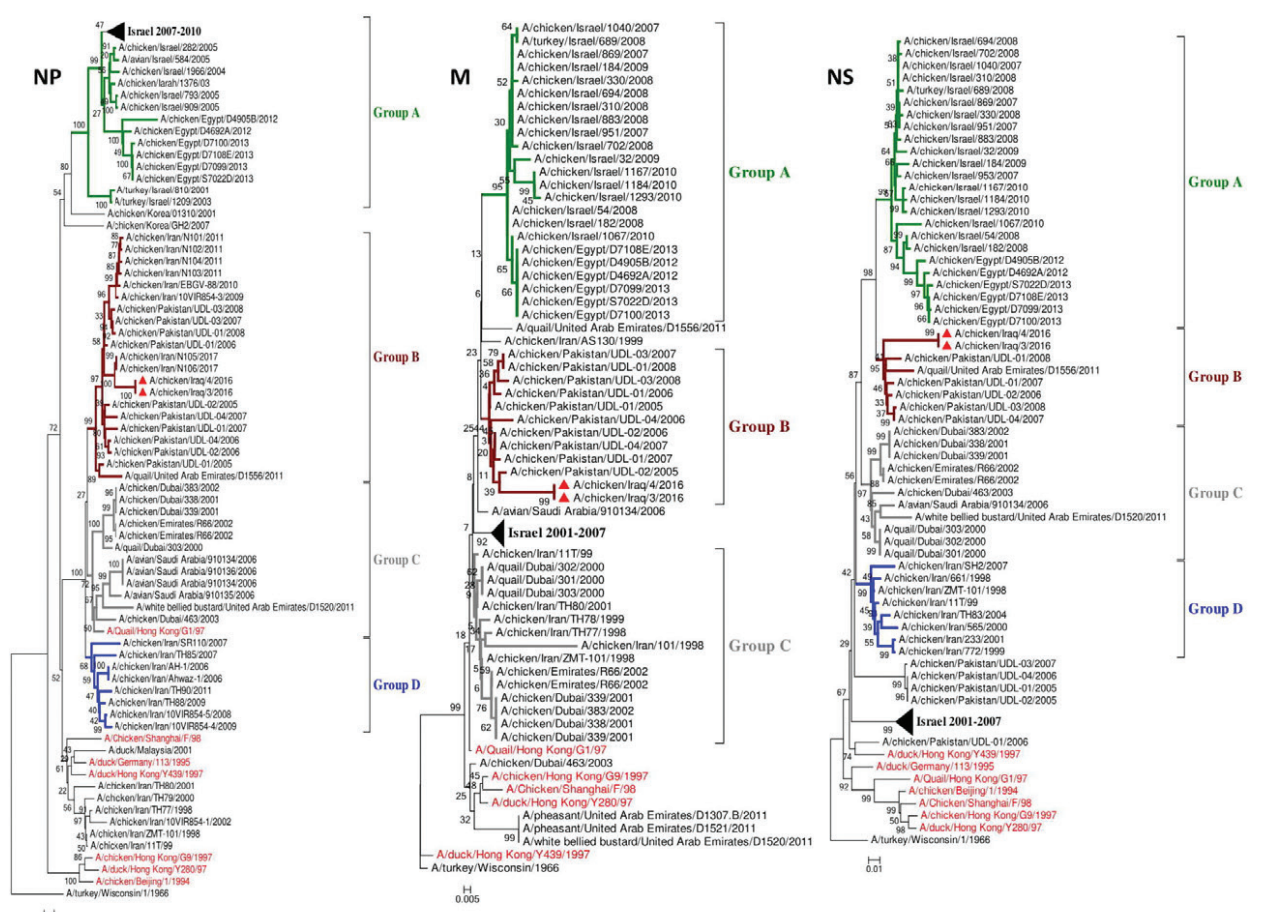

$\stackrel{\leftrightarrow 60}{0.01}$

Fig. 2. Phylogenetic trees of the nucleotide sequences of PB2, PB1, PA, NP, M, and NS segments of H9N2 viruses isolated from Iraq comparing with representative H9N2 viruses isolated from different Asian and Middle Eastern countries. H9N2 isolates sequenced specifically for this study are labeled in red triangles. Reference H9N2 viruses were labeled with red color. The phylogenetic analysis was performed by using MEGA version 6. Four distinct groups A, B, C, and D of G1-like H9N2 viruses were distinguished by green, maroon, gray, and blue colors, respectively. 
sequences of the current H9N2 viruses from Iraq. The HA cleavage motif sequences of the current Iraqi H9N2 isolates were PAKSSR/GLF (denotes site of protease activity between HA1 and HA2), which have been associated with low pathogenicity. The receptor binding site in the HA is critical for host receptor preference. Substitutions of amino acid located within the receptor binding site [Q183/191H, T189/197A, A190/198E, Q226/234L, and G228/236S (H3/H9 numbering)] are critical for transmission of AI H9N2 viruses in ferrets (Wan et al., 2008). Similar to other Middle Eastern and Asian H9N2 viruses, the Iraqi H9N2 isolates had H191 and L234 (H9 numbering) which are associated with a preferential binding to cellular receptor in humans and 197T, 198A, and G236 associated with avian like receptor (Sorrell et al., 2009). Like human and avian H9N2 viruses isolated from different regions (Kandeil et al., 2017), Iraqis H9N2 isolate had a higher binding preference for $\alpha 2,6$-SL than $\alpha 2,3$-SL indicating this virus has stronger binding specificity toward human like receptor (Fig. 3).

The HA protein was examined for the presence of potential glycosylation sites, with the N-X-T/S-X sequence, where $\mathrm{X}$ is any amino acid other than proline. The H9N2 viruses had six potential glycosylation sites at positions 29, 105, 141, 298, 305, and 492. No stalk deletions were detected in the NA segment, and the Iraqi H9N2 viruses did not display NA resistance mutations (McKimm-Breschkin, 2013). A substitution of V to I at site 504 of PB2 correlates with increasing activity of viral polymerase complex and this mutation was recorded in newly characterized H9N2 virus from Iraq (Rolling et al., 2009). Both H9N2 isolates had substitution G309D in PB2 that enhance virus replication in the human lung cells (Yamaji et al., 2015). The PB1 segment of the Iraqi H9N2 isolates expressed PB1-F2 protein of 90 amino acids. Screening of molecular markers in the M2 ion channel protein which play an essential role in resistance of influenza A viruses to adamantine drugs including revealed that
Iraqi isolates contain V27A substitution that might confer amantadine resistance. Both isolates had KPEI motif at C-terminal of NS1 protein and harbored the mammalian-specific E227K substitution. P42S, L103F, and V149A mutations in the NS1 protein associated with virulence and pathogenicity in mammals (Seo et al., 2002; Jiao et al., 2008) were detected in both H9N2 isolates (Table 1).

Like genetic analysis of Iraqis isolates, antigenic mapping based on the HI results of hyperimmune sera raised against different strains of H9N2 viruses showed the close relationship of circulating H9N2 viruses in Iraq (Fig. 4). The antigenic map showed a close relationship among recently characterized H9N2 viruses in Iraq and chronologically circulating H9N2 viruses in Lebanon and Egypt (Fig. 4). Generally, there is a close relationship between genetic and antigenic analysis, but the antigenic distance which based on only a single amino acid could be an uncertain predictor of the significant genetic dissimilarity. A previous study showed that any change of the nine amino acids [antigenic site $\mathrm{A}(143,166,170)$, antigenic site B $(153,201,234)$, and overlapping site $(141,197$, 206)] of the H9 HA glycoprotein led to the appearance of a new variant (Kaverin et al., 2004). Although the antigenic site B (II) of Iraqi H9N2 viruses has D153N substitution, no antigenic drift of these isolates was recorded based on the cross reactivity of the Iraqis H9N2 viruses with antibodies.

Iraq imports poultry from neighboring countries such as Iran which may accuse in virus transmission to Iraq poultry. The high similarity between detected virus in Iraq and endemic H9N2 viruses in Pakistan and Iran indicates that circulating H9N2 viruses in the Middle East and Central Asia have the same virus ancestor. The Trade of live poultry among the Central Asian and Middle Eastern countries and wild bird migrations play a major role in transmission of H9N2 viruses among these countries. The PB1 segments of the H9N2 viruses in Iraq were not related to any of the previously
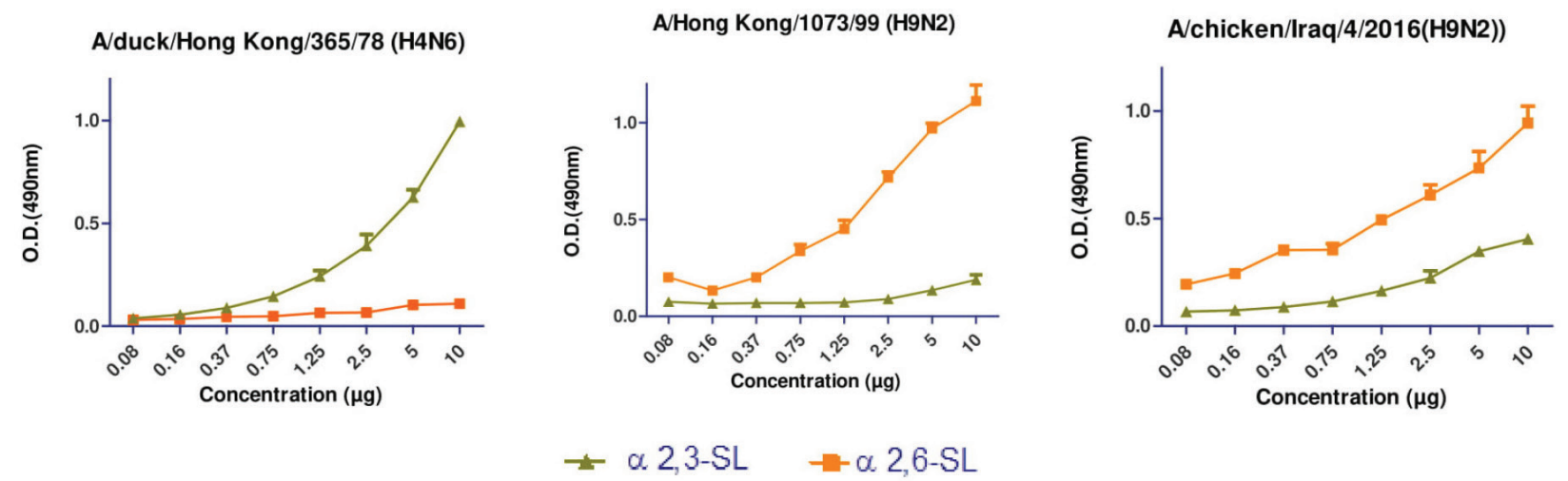

Fig. 3. Receptor-binding specificity of Iraqis H9N2 virus to biotinylated sialylglycopolymers 3'-sialyllactose ( $\alpha 2,3-\mathrm{SL})$, and 6'-sialyllactose ( $\alpha 2,6-\mathrm{SL}$ ), comparing with avian A/duck/Hong Kong/365/78 (H4N6) and a human A/Hong Kong/1073/99 (H9N2) isolates. 
Table 1. Analysis of virulence genetic markers in the viral PB2, PB1, PA, M2, NS1, and NS2 proteins in H9N2 isolated from Iraq.

\begin{tabular}{|c|c|c|c|c|c|}
\hline Protein & aa Site & Virulent & A virulent & H9N2 & Reference \\
\hline \multirow{6}{*}{ PB2 } & 627 & $\mathrm{~K}$ & $\mathrm{E}$ & $\mathrm{E}$ & (Wang et al., 2012) \\
\hline & 147 & $\mathrm{~L}$ & M & $\mathrm{V}$ & (Wang et al., 2012) \\
\hline & 250 & G & $\mathrm{V}$ & $\mathrm{V}$ & (Wang et al., 2012) \\
\hline & 504 & $\mathrm{~V}$ & I & $\mathrm{V}$ & (Rolling et al., 2009) \\
\hline & 701 & $\mathrm{~N}$ & $\mathrm{D}$ & $\mathrm{D}$ & (Zhou et al., 2013) \\
\hline & 591 & $\mathrm{~K}$ & Q & $\mathrm{P}$ & (Mok et al., 2014) \\
\hline PB1 & 317 & I & $\mathrm{M} / \mathrm{V}$ & M & (Chen et al., 2006; Lee et al., 2007) \\
\hline \multirow{4}{*}{ PA } & 127 & $\mathrm{~V}$ & I & $\mathrm{V}$ & (Lycett et al., 2009) \\
\hline & 672 & $\mathrm{~L}$ & $\mathrm{~F}$ & $\mathrm{~L}$ & (Li et al., 2005) \\
\hline & 100 & $\mathrm{R}$ & $\mathrm{V}$ & $\mathrm{V}$ & (Otte et al., 2015) \\
\hline & 550 & $\mathrm{~L}$ & I & I & (Rolling et al., 2009) \\
\hline \multirow{2}{*}{ M2 } & 64 & $\mathrm{~S} / \mathrm{A} / \mathrm{F}$ & $\mathrm{P}$ & $\mathrm{S}$ & (Lycett et al., 2009) \\
\hline & 69 & $\mathrm{P}$ & $\mathrm{L}$ & $\mathrm{P}$ & (Lycett et al., 2009) \\
\hline \multirow{5}{*}{ NS1 } & 42 & $\mathrm{~S}$ & $\mathrm{~A} / \mathrm{P}$ & $\mathrm{S}$ & (Jiao et al., 2008) \\
\hline & 92 & $\mathrm{E}$ & $\mathrm{D}$ & $\mathrm{D}$ & (Lee et al., 2007) \\
\hline & 103 & $\mathrm{~L}$ & $\mathrm{~F}$ & $\mathrm{~L}$ & (Dankar et al., 2011) \\
\hline & 106 & I & M & M & (Dankar et al., 2011) \\
\hline & 189 & $\mathrm{~N}$ & $\mathrm{D} / \mathrm{G}$ & $\mathrm{D}$ & (Subbarao and Shaw, 2000) \\
\hline \multirow{2}{*}{ NS2 } & 31 & I & M & M & (Subbarao and Shaw, 2000) \\
\hline & 56 & $\mathrm{Y}$ & $\mathrm{H} / \mathrm{L}$ & $\mathrm{H}$ & (Subbarao and Shaw, 2000) \\
\hline
\end{tabular}

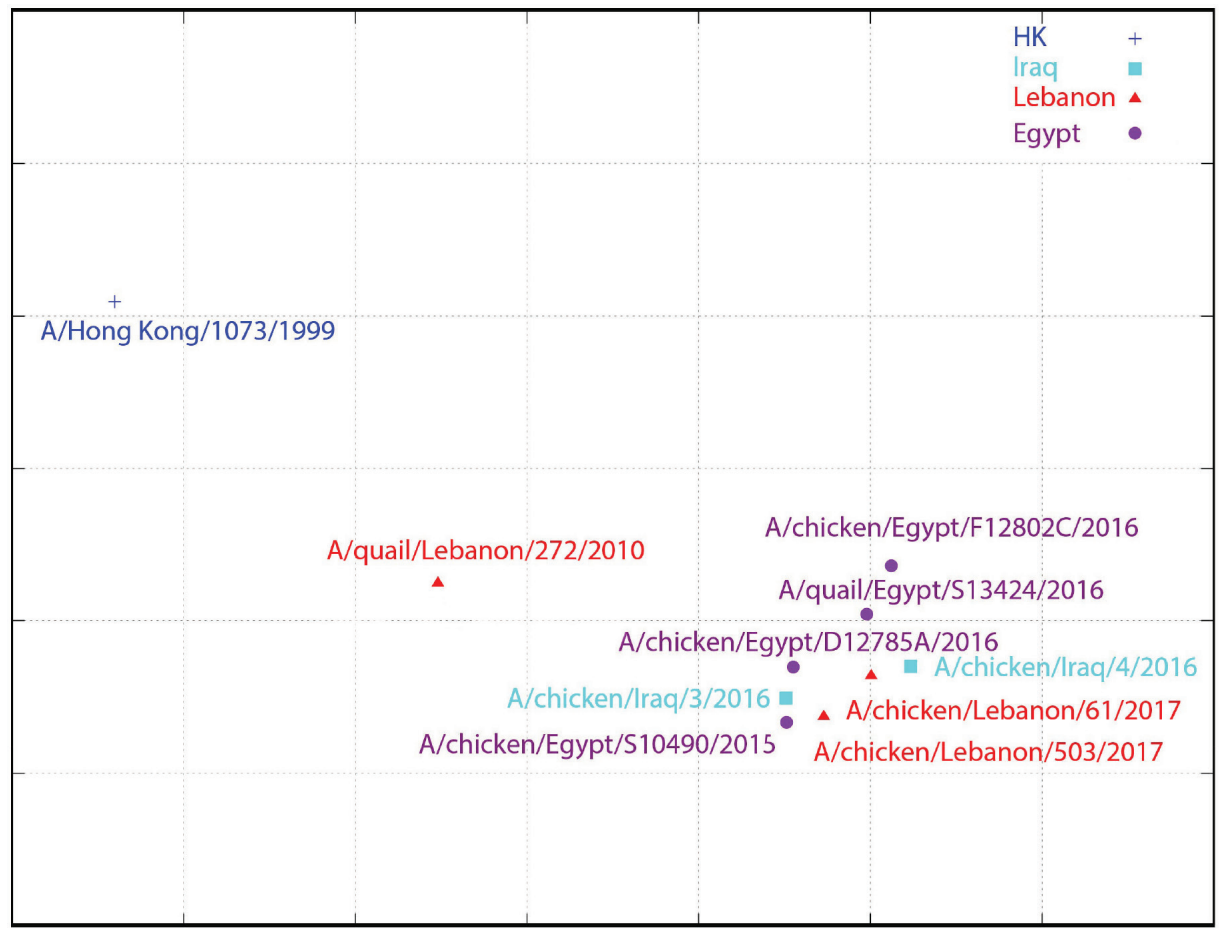

Fig. 4. Antigenic cartography of the detected H9N2 viruses in Iraq and their relationship with contemporary H9N2 viruses isolated from Egypt and Lebanon. The maps were generated by using Antigen Map (http://sysbio.cvm.msstate.edu/AntigenMap) using HI data. One unit (grid) represents a twofold change in the HI assay results. (HK): Hong Kong. 
characterized H9N2 viruses. Active surveillance of AIV in poultry and migratory birds should be adopted to monitor the genesis and emergence of new strains in Iraq.

\section{Acknowledgements}

The authors wish to thank all the field staffs who collected the samples from Iraq. This work is funded by the Egyptian Science and Technology Development Fund (under grant no. 5175) and National Institute of Allergy and Infectious Diseases, National Institutes of Health, Department of Health and Human Services, under contract number HHSN272201400006C.

\section{Author contributions}

NSM, AK, GK, and MA conceived and designed the study; IZ and his team collected samples; NSM and AK performed the experiments and sequencing analysis; all authors contributed to the writing and revision of the manuscript and approved the final one.

\section{Conflict of interest}

The authors declare that there is no conflict of interest. Ethical approval

This article does not contain any studies with human/ animal participants performed by any of the authors.

\section{References}

Abdul-Sada, K.M. 2015. Surveillance of influenza A/ $\mathrm{H} 5, \mathrm{H} 7, \mathrm{H} 9$ viral subtypes in domestic and wild birds at many geographical regions of Iraq. Int. J. Adv. Res. 3, 170-176.

Al-Dabhawe, A.H., Kadhim, H.M. and Samaka, H.M. 2013. Molecular detection of infectious bronchitis virus and it is relation with avian influenza virus (H9) and Mycoplasma gallisepticum from different geographical regions in Iraq. Iraqi J. Vet. Sci. 27, 97-101.

Al-Mohana, A.M., Kadhimv, H.M., H.K., Al-Charrakh, A.H., Al- Habubi, Z., Nasir, F.H., Al-Hilali, S.A. and Hadi, Z.J. 2013. Molecular diagnosis of avian respiratory diseases in commercial broiler chicken flocks in province of Najaf, Iraq. Sci. Res. Essays 8, 1191-1195.

Cai, Z., Zhang, T. and Wan, X.F. 2011. Concepts and applications for influenza antigenic cartography. Influenza Other Respir. Viruses 5(Suppl 1), 204207.

CDC. 2007. CDC realtime RTPCR protocol for detection and characterization of influenza., I-00705., N., ed. (Atlanta).

Chen, G.W., Chang, S.C., Mok, C.K., Lo, Y.L., Kung, Y.N., Huang, J.H., Shih, Y.H., Wang, J.Y., Chiang, C., Chen, C.J. and Shih, S.R. 2006. Genomic signatures of human versus avian influenza A viruses. Emerg. Infect. Dis. 12, 1353-1360.

Dankar, S.K., Wang, S., Ping, J., Forbes, N.E., Keleta, L., Li, Y. and Brown, E.G. 2011. Influenza A virus NS1 gene mutations F103L and M106I increase replication and virulence. Virol. J. 8, 13.
Fusaro, A., Monne, I., Salviato, A., Valastro, V., Schivo, A., Amarin, N.M., Gonzalez, C., Ismail, M.M., AlAnkari, A.R., Al-Blowi, M.H., Khan, O.A., Maken Ali, A.S., Hedayati, A., Garcia Garcia, J., Ziay, G.M., Shoushtari, A., Al Qahtani, K.N., Capua, I., Holmes, E.C. and Cattoli, G. 2011. Phylogeography and evolutionary history of reassortant H9N2 viruses with potential human health implications. J. Virol. 85, 8413-8421.

Gomaa, M.R., Kandeil, A., El-Shesheny, R., Shehata, M.M., McKenzie, P.P., Webby, R.J., Ali, M.A. and Kayali, G. 2018. Evidence of infection with avian, human, and swine influenza viruses in pigs in Cairo, Egypt. Arch. Virol. 163, 359-364.

Guo, Y.J., Wen, L.Y., Zhang, Y., Wan, M., Guo, J.F., Li, Z. and Shu, Y.L. 2005. [Do pigs play a role in human infection with avian influenza A H9N2 viruses]. (Article in Chinese). Zhonghua Shi Yan He Lin Chuang Bing Du Xue Za Zhi. 19, 106-109.

Hoffmann, E., Stech, J., Guan, Y., Webster, R.G. and Perez, D.R. 2001. Universal primer set for the fulllength amplification of all influenza A viruses. Arch. Virol. 146, 2275-2289.

Homme, P.J. and Easterday, B.C. 1970. Avian influenza virus infections. I. Characteristics of influenza A-turkey-Wisconsin-1966 virus. Avian Dis. 14, 66-74.

Jiao, P., Tian, G., Li, Y., Deng, G., Jiang, Y., Liu, C., Liu, W., Bu, Z., Kawaoka, Y. and Chen, H. 2008. A single-amino-acid substitution in the NS1 protein changes the pathogenicity of H5N1 avian influenza viruses in mice. J. Virol. 82, 1146-1154.

Kandeil, A., El-Shesheny, R., Maatouq, A., Moatasim, Y., Cai, Z., McKenzie, P., Webby, R., Kayali, G. and Ali, M.A. 2017. Novel reassortant H9N2 viruses in pigeons and evidence for antigenic diversity of H9N2 viruses isolated from quails in Egypt. J. Gen. Virol. 98, 548-562.

Kaverin, N.V., Rudneva, I.A., Ilyushina, N.A., Lipatov, A.S., Krauss, S. and Webster, R.G. 2004. Structural differences among hemagglutinins of influenza A virus subtypes are reflected in their antigenic architecture: analysis of H9 escape mutants. J. Virol. 78, 240-249.

Kayali, G., Kandeil, A., El-Shesheny, R., Kayed, A.S., Gomaa, M.M., Maatouq, A.M., Shehata, M.M., Moatasim, Y., Bagato, O., Cai, Z., Rubrum, A., Kutkat, M.A., McKenzie, P.P., Webster, R.G., Webby, R.J. and Ali, M.A. 2014. Active surveillance for avian influenza virus, Egypt, 20102012. Emerg. Infect. Dis. 20, 542-551.

Khamas, E. 2008. Avian influenza (H9N2) outbreak In Iraq. Iraqi J. Vet. Sci. 32, 223-230.

Kraidi, Q.A., Madadgar, O., Ghalyanchi Langeroudi, A. and Karimi, V. 2017. Genetic analysis of H9N2 avian influenza viruses circulated in broiler flocks: a case study in Iraq in 2014-2015. Virus Genes 53, 205-214. 
Lee, M.S., Deng, M.C., Lin, Y.J., Chang, C.Y., Shieh, H.K., Shiau, J.Z. and Huang, C.C. 2007. Characterization of an $\mathrm{H} 5 \mathrm{~N} 1$ avian influenza virus from Taiwan. Vet. Microbiol. 124, 193-201.

Lee, D.H., Swayne, D.E., Sharma, P., Rehmani, S.F., Wajid, A., Suarez, D.L. and Afonso, C. 2016. H9N2 low pathogenic avian influenza in Pakistan (20122015). Vet. Rec. Open 3, e000171.

Li, Z., Chen, H., Jiao, P., Deng, G., Tian, G., Li, Y., Hoffmann, E., Webster, R.G., Matsuoka, Y. and Yu, K. 2005. Molecular basis of replication of duck $\mathrm{H} 5 \mathrm{~N} 1$ influenza viruses in a mammalian mouse model. J. Virol. 79, 12058-12064.

Lycett, S.J., Ward, M.J., Lewis, F.I., Poon, A.F., Kosakovsky Pond, S.L. and Brown, A.J. 2009. Detection of mammalian virulence determinants in highly pathogenic avian influenza $\mathrm{H} 5 \mathrm{~N} 1$ viruses: multivariate analysis of published data. J. Virol. 83, 9901-9910.

Matrosovich, M.N. and Gambaryan, A.S. 2012. Solidphase assays of receptor-binding specificity. Methods Mol. Biol. 865, 71-94.

McKimm-Breschkin, J.L. 2013. Influenza neuraminidase inhibitors: antiviral action and mechanisms of resistance. Influenza Other Respir. Viruses 7(Suppl 1), 25-36.

Mok, C.K.P., Lee, H.H.Y., Lestra, M., Nicholls, J.M., Chan, M.C.W., Sia, S.F., Zhu, H., Poon, L.L.M., Guan, Y. and Peiris, J.S.M. 2014. Amino acid substitutions in polymerase basic protein 2 gene contribute to the pathogenicity of the novel A/ H7N9 influenza virus in mammalian hosts. J. Virol. 88, 3568-3576.

Naeem, K., Ullah, A., Manvell, R.J. and Alexander, D.J. 1999. Avian influenza A subtype H9N2 in poultry in Pakistan. Vet. Rec. 145, 560.

OIE. 2015. Immediate notification highly pathogenic avian influenza in Germany.

Otte, A., Sauter, M., Daxer, M.A., McHardy, A.C., Klingel, K. and Gabriel, G. 2015. Adaptive mutations that occurred during circulation in humans of H1N1 influenza virus in the 2009 pandemic enhance virulence in mice. J. Virol. 89, 7329-7337.

Peiris, M., Yuen, K.Y., Leung, C.W., Chan, K.H., Ip, P.L., Lai, R.W., Orr, W.K. and Shortridge, K.F. 1999. Human infection with influenza H9N2. Lancet 354, 916-917.

Rolling, T., Koerner, I., Zimmermann, P., Holz, K., Haller, O., Staeheli, P. and Kochs, G. 2009. Adaptive mutations resulting in enhanced polymerase activity contribute to high virulence of influenza A virus in mice. J. Virol. 83, 6673-6680.
Saito, T., Lim, W., Suzuki, T., Suzuki, Y., Kida, H., Nishimura, S.I. and Tashiro, M. 2001. Characterization of a human H9N2 influenza virus isolated in Hong Kong. Vaccine 20, 125-133.

Seo, S.H., Hoffmann, E. and Webster, R.G. 2002. Lethal H5N1 influenza viruses escape host anti-viral cytokine responses. Nat. Med. 8, 950-954.

Sorrell, E.M., Wan, H., Araya, Y., Song, H. and Perez, D.R. 2009. Minimal molecular constraints for respiratory droplet transmission of an avian-human H9N2 influenza A virus. Proc. Natl. Acad. Sci. U. S. A. 106, 7565-7570.

Subbarao, K. and Shaw, M.W. 2000. Molecular aspects of avian influenza (H5N1) viruses isolated from humans. Rev. Med. Virol. 10, 337-348.

Tamura, K., Peterson, D., Peterson, N., Stecher, G., Nei, M. and Kumar, S. 2011. MEGA5: molecular evolutionary genetics analysis using maximum likelihood, evolutionary distance, and maximum parsimony methods. Mol. Biol. Evol. 28, 27312739.

Wan, H., Sorrell, E.M., Song, H., Hossain, M.J., Ramirez-Nieto, G., Monne, I., Stevens, J., Cattoli, G., Capua, I., Chen, L.M., Donis, R.O., Busch, J., Paulson, J.C., Brockwell, C., Webby, R., Blanco, J., Al-Natour, M.Q. and Perez, D.R. 2008. Replication and transmission of H9N2 influenza viruses in ferrets: evaluation of pandemic potential. PLoS One 3, e2923.

Wang, J., Sun, Y., Xu, Q., Tan, Y., Pu, J., Yang, H., Brown, E.G. and Liu, J. 2012. Mouse-adapted H9N2 influenza A virus PB2 protein M147L and E627K mutations are critical for high virulence. PLoS One 7, e40752.

Wu, H., Peng, X., Cheng, L., Lu, X., Jin, C., Xie, T., Yao, H. and $\mathrm{Wu}$, N. 2015. Genetic and molecular characterization of H9N2 and H5 avian influenza viruses from live poultry markets in Zhejiang Province, eastern China. Sci. Rep. 5, 17508.

Yamaji, R., Yamada, S., Le, M.Q., Li, C., Chen, H., Qurnianingsih, E., Nidom, C.A., Ito, M., Sakai-Tagawa, Y. and Kawaoka, Y. 2015. Identification of PB2 mutations responsible for the efficient replication of $\mathrm{H} 5 \mathrm{~N} 1$ influenza viruses in human lung epithelial cells. J. Virol. 89, 3947-3956.

Zhou, B., Pearce, M.B., Li, Y., Wang, J., Mason, R.J., Tumpey, T.M. and Wentworth, D.E. 2013. Asparagine substitution at PB2 residue 701 enhances the replication, pathogenicity, and transmission of the 2009 pandemic H1N1 influenza A virus. PLoS One 8, e67616. 